\title{
Is it really happening here? A study of climate change perception in the Azores
}

\author{
R. T. Cunha ${ }^{1}$, B. Rangel ${ }^{2}$, O. Vieira $^{2} \&$ I. E. Rego ${ }^{1}$ \\ ${ }^{I}$ CIBIO Azores - Research Center for Biodiversity and Genetic \\ Resources, University of the Azores, Portugal \\ ${ }^{2}$ Geography Section, Department of Biology, University of the Azores, \\ Portugal
}

\begin{abstract}
In EC countries, energy production and transport are responsible for the major production of GHG emissions. The last report of IPCC on climate change and water suggests that changes in lifestyle, behavior patterns and management practices can contribute to climate change mitigation across all sectors. The present study aims at understanding how Azoreans perceive climate change as well as their responsibility in both the production and the reduction of GHG emissions through a survey conducted in the island of São Miguel. A questionnaire was used to capture people's conceptions, affect, sense of trust, and responsibility regarding climate change and the results were analyzed according to environmental and socio-demographic variables. The findings indicate that even though participants report being most concerned with poverty and food and water shortage in the world, they are afraid of Global Climate Change (GCC). Their perceptions indicate that the vast majority (1) has a very good understanding of GCC processes; (2) believe GCC is a serious threat very much linked to human activities, affects most other distant parts of the world and dangerous impacts are already happening; and (3) think they are reasonably well informed, get information mainly through the media and trust the media more than any other source of environmental information. Most participants report having taken action to fight GCC but that tendency is not expressed in daily domestic behavior. Responsibility for acting against GCC is mainly attributed to external powerful agents rather than to citizens and their communities.
\end{abstract}

Keywords: perceptions, climate change, mitigation, islands, Azores, Portugal. 


\section{Introduction}

Global Climate Change (GCC) is a problem whose consequences may be less severe if mitigation and adaptation measures are planned and applied in accordance to local or regional specificities.

.....In the last decades, the debate over GCC has spread, intensified and become public, with the prevailing objective and correct assessment of situations done by scientists being challenged by lay people's inaccurate and subjective notions. Regardless of differences in perspectives, they all agree that future impacts of GCC may be much more destructive if people do not learn how to change their behavior (IPCC [1]).

Extensive research has addressed the human/social dimension of GCC and pointed out the need to better understand people's environmental perceptions, feelings and behavior (e.g. Böhm and Pfister [2]; Leiserowitz [3]; Lowe [4]).

Proenvironmental behavior is guided by worries about future consequences of global environmental change and, particularly negative consequences for humans more than knowledge about the probability of occurrence of unwanted events or behaviors leading to these events (e.g. Böhm and Pfister [2]; Sjöberg [5]).

When a threat is perceived as being greater than the capacity to deal with it, feelings of fear and anxiety may activate defensive reactions and the denial/minimization of threat (Lowe [4]). On the other hand, when the importance of a topic is high but confidence in knowledge supporting attitudes is low, there is a tendency to restore balance by engaging in systematic seeking and processing of information (Chaiken et al [6]; Sundblad et al [7]).

Knowledge and confidence in one's knowledge regarding environmental risks and coping with risk situations are key factors to behave more proenvironmentally (Sundblad [7]). Also, trust has been shown to be a crucial factor influencing the perception of environmental risk, effective risk communication and attitudes regarding risk management policy (e.g. Renn and Levine [8]; Kasperson [9]; Slovic [10]; Breakwell [11]). However, studies have not yet sufficiently examined public confidence in climate scientists, and the role of personal efficacy in affecting global warming outcomes (Kellstedt et al [12]).

The effects of climate change are global but islands and archipelagos are more prone to suffer adverse impacts, mainly related to water scarcity, because, in addition to their geographic position, many are already constrained by other variables, such as small size, remoteness, tourist pressure or biotic invasions.

Located in the North Atlantic, $1400 \mathrm{~km}$ away from mainland Europe (Lisboa) and $1900 \mathrm{~km}$ from North America (Newfoundland), the Portuguese archipelago of the Azores is located between the latitudes of $36^{\circ} 55^{\prime}$ e $39^{\circ} 45^{\prime} \mathrm{N}$ and the longitudes of $24^{\circ} 45^{\prime} \mathrm{W}$ and $31^{\circ} 17^{\prime} \mathrm{W}$, and comprises nine islands of oceanic volcanic origin, distributed by three groups, the Western group (Flores and Corvo), the Central group (Pico, Faial, Terceira, São Jorge and Graciosa) and the Eastern group (São Miguel and Santa Maria). The emerged area of the archipelago is $2344 \mathrm{~km}^{2}$, with the islands varying in size from $17 \mathrm{~km}^{2}$ (Corvo) to $747 \mathrm{~km}^{2}$ (São Miguel), with Pico holding the highest mountain of Portugal (2351m) (Instituto Hidrográfico [13]). Due to the influence of the warm Gulf 
stream and the Azores Anticyclone, the climate of the archipelago is temperate, mainly during late spring and summer (Santos et al [14]).

The Azores were populated from Portugal mainland after the XV century and today have a population of approximately 242.000 , distributed by the nine islands, being Corvo the least populated - 300 inhabitants, and São Miguel, the most populated, with $54,6 \%$ of the total inhabitants of the archipelago (SREA [15]).

In 2007, the Azores was considered the second best archipelago in the world for sustainable tourism, by the National Geographic Traveller. This evaluation was based on the islands' scenic attributes and light tourist pressure, a consequence of their remoteness and temperate weather that does not encourage mass flux of beach tourism. The archipelago belongs to the biogeographical region of Macaronesia, along with Madeira, the Canary Islands and Cape Vert, and is the most important biodiversity hotspot of the top 25 world biodiversity hotspots (Myers et al [16]).

Concerning climate change scenarios for the Azores, the major estimated impact of global warming is expected to affect annual precipitation distribution, with wetter winters and drier remaining seasons, a situation that will have an effect on water resources. Severe precipitation events in winter and water deficit in summer will aggravate landslides events, already frequent in the islands. The impacts of climate change on the temperature are thought to be less severe since the archipelago will benefit from the protection of the sea (Santos et al [14]).

In this view, climate change studies in the Azores are considered to be very relevant because the islands depend greatly on their natural resources, namely on fresh water, and its economy is based on agriculture, fisheries, services, and on the recent and expanding industry of tourism.

The majority of energy production and consumption (79\%) are of thermoelectric (fuel) origin and the remaining energy demand is satisfied by diversified renewable sources, which are expected to increase in the future. A recent report by Regional Secretary of the Environment and the Sea (SRAM [17]) highlighted the importance of fuel derived energy production and consumption for the generation of Greenhouse Gases (GHG) emissions in the Azores, mainly trough transports and energy industry (47\% and $39 \%$, respectively). Concerning transports and as a consequence of the dominant pattern of mobility in most of the islands (e.g. low active mobility, high individual car acquisition, incipient public transport services), road traffic is responsible for $74 \%$ of $\mathrm{GHG}$ emissions and, together with the increase of individual car acquisition, represents a major stressing factor in the sector. GHG emissions from 'other activities' - domestic, services, agriculture and fisheries also tend to increase, with domestic and services representing over $85 \%$ of total emissions between 1998 and 2004. The island of São Miguel represents over $50 \%$ of the Azores' $\mathrm{GHG}$ and $\mathrm{CO}_{2}$ emissions.

In order to slow those emissions, an increase in energy efficiency and renewable sources, and a decrease in energy consumption are considered relevant measures. According to the last report of IPCC on climate change and water there is "high agreement and medium evidence that changes in lifestyle, 
behaviour patterns and management practices can contribute to climate change mitigation across all sectors" (Bates et al [18]).

The main aims of this study are: i) to understand how the inhabitants of the São Miguel island (Azores) perceive climate change as well as their responsibility in both the production and the reduction of GHG emissions; and ii) to contribute to the promotion of new attitudes and behaviors towards climate change mitigation and adaptation in the island, thus contributing for a better environment in the Azores.

Four main study questions were addressed in the study:

1) How is GCC perceived? (Knowledge about the causes, effects, and ways of fighting the phenomenon; Perception of the seriousness of the phenomenon);

2) What feelings are associated to GCC? (Concern / Fear)

3) What action is being/should be carried out regarding GCC? (What should be done? Who is responsible for taking action?)

4) Who are trustful sources of information regarding GCC?

\section{Method}

A survey was conducted in São Miguel, mainly through a person to person distribution of questionnaires, from December 2008 to March 2009, in four of the six municipalities of the island (Ponta Delgada, Ribeira Grande, Lagoa and Vila Franca), representing approximately $80 \%$ of the island's population (SREA, 2007).

The questionnaire $(\mathrm{N}=140$; return ratio of $93,3 \%)$ consisted of 18 questions (varying from Likert scale to multiple-choice items), with four questions dedicated to the socio-demographic characterization of the sample (sex, age, educational level and place of residence) and the remaining 16 focusing on relevant behavioral dimensions based on research and findings from the literature in the field (Lowe [4]; Figueiredo [19]; Special Eurobarometer 300 [20]).

The majority of survey participants were female $(68,57 \%)$, belonging to the age group $26-64 \mathrm{yrs}(60,14 \%$ vs. $38,41 \%$ in $15-25 \mathrm{yrs}$ and $1,45 \% \geq 65 \mathrm{yrs})$, had a superior degree $\left(47,10 \%\right.$ vs. $3,62 \%$ at the $1^{\text {st }}$ level; $2,17 \%$ at the $2^{\text {nd }}$ level; $13,77 \%$ at the $3^{\text {rd }}$ level and $33,33 \%$ at the Secondary level) and lived in Ponta Delgada $(79,29 \%$ vs. $13,57 \%$ in Ribeira Grande; $2,86 \%$ in Vila Franca do Campo and 4,29\% in Lagoa).

\section{Findings and discussion}

In order to address the first study question "How is GCC perceived?" several dimensions were investigated: the causes of GCC; the seriousness of the threat; the consequences of GCC; how much is being done to fight GCC by different entities and aspects related to knowledge/information about GCC.

Asked about the nature of causes promoting GCC, the respondents elected a combination of natural and human causes (55\%) and choose greenhouse gas emissions $(95,7 \%)$ as the most important factor directly contributing to GCC, followed by burning of fossil fuels $(87,9 \%)$ and deforestation $(87,1 \%)$. These 
results are not in line with others reporting on low level of understanding of GCC causes (Futerra [21]).

Most of the respondents believed GCC is a very serious threat $(60,0 \%$ against $75 \%$ in UE27 and Portugal mainland), disagreed that GCC has been overemphasized (42,9\% against 34\% in UE27 and 38\% in Portugal mainland) but did not consider GCC as the most serious problem the world is facing, electing poverty, food and water shortage in first place $(67,1 \%)$, which is consistent with data from UE27 (68\%) and Portugal mainland (73\%) (Special Eurobarometer 300 [20]).

For the majority of the respondents, the consequences of GCC will affect 'a lot' the world population $(67,9 \%)$, non-human nature $(75,0 \%)$ and situations ranging from 'oneself and family' to the 'Europeans' $(47,9 \%$ to $52,9 \%)$ and believed dangerous impacts of GCC have already started $(85,0 \%)$, disagreeing with Futerra's [21] finding that the majority believes GCC will mainly affect future generations. The chance that more intense storms, hurricanes and tornadoes will occur during the next 50 years was considered 'very high' by $66,4 \%$ of the respondents, but an increase in the sea rise level $(58,6 \%)$ and flooding of major cities $(51,4 \%)$ were seen as having a high probability of occurring. Respondents also reported that, for the same period, there was a 'high chance' that standards of living would decrease $(59,3 \%)$ and a food shortage could occur $(58,6 \%)$.

When asked about 'how much' is being done by different entities to fight GCC, the majority of respondents ranked the following entities as 'not doing enough': corporations and industry $(90,7 \%)(76 \%$ in EU27 and $74 \%$ in Portugal mainland); the government $(89,3 \%)(64 \%$ in EU27 and $68 \%$ in Portugal mainland) and citizens (86,4\%) (58\% in EU27 and 60\% in Portugal mainland).

Questioned about their knowledge/information concerning GCC, the majority of respondents was 'fairly well informed' about causes $(70,7 \%)$, consequences $(69,3 \%)$ and forms of fighting $(61,4 \%)$ GCC, evidencing a slightly higher confidence in their knowledge than lay persons in other research (Sundblad et al [7]). The majority also listed as main sources of information TV $(23,6 \%)$, which agrees with findings in US, Europe and South America, followed by Internet $(16,8 \%)$, newspapers and magazines $(16,0 \%)$ and school $(10,7 \%)$.

To address the second study question 'What feelings are associated to GCC?', fear and problems regarding GCC one worries about most were investigated. Asked if they were afraid of GCC, the majority of respondents agreed $(61,4 \%)$ but they choose poverty, food and water shortage $(85,2 \%)$ as their first and second choices for problems one worries about most.

The third study question 'What should be done regarding GCC?' aimed at evaluating if Azoreans are taking action to help fighting GCC, what prevent them from acting against GCC and their responsibility for doing something.

The majority believed they have taken action to help fighting GCC (64,3\% vs. $47 \%$ in EU27 and Portugal mainland) and elected as main actions reducing water consumption at home $(22,5 \%$, vs. $55 \%$ in EU27 and 52\% in Portugal mainland), followed by recycling most of the domestic waste $(20,5 \%$ vs. $76 \%$ in EU27 and $60 \%$ in Portugal mainland) and reducing energy consumption at home $(17,4 \mathrm{vs}$. 
$64 \%$ in EU27 and 50\% in Portugal mainland). These findings suggest that practices dedicated to reduce water consumption, recycling most of the domestic waste and reducing energy consumption at home do not play yet an important role in São Miguel because they were much lower than those found in similar studies in EU 27 and Portugal mainland (Special Eurobarometer 300 [20]).

Questioned about what prevents one from acting against GCC, the majority considered that they would like to take action but 'do not know what to do" (24,9\% vs. $34 \%$ in EU27 and 29\% in Portugal mainland), followed by those who think that 'governments, corporations and industries should change their behavior rather than the citizens' $(20,1 \%$ vs. $42 \%$ in EU27 and $40 \%$ Portugal mainland, in both situations choose preventing one from 'acting against GCC' in the first place). Finally, some participants thought that 'changing their behavior does not affect climate change'(18,7\% vs. $26 \%$ in EU27 and $21 \%$ in Portugal mainland).

Considering the degree of responsibility for doing something about GCC, respondents identified as 'very much' responsible more polluting countries $(83,6 \%)$, oil companies $(73,6 \%)$ and developed countries $(69,3 \%)$.

For the last study question 'Who are trustful sources of information regarding GCC?' respondents were asked to classify their trust or distrust on distinct groups and entities and the majority somewhat trust most radio $(85,0 \%)$, followed by TV $(82,1 \%)$ and newspapers/magazines $(80,7 \%)$; these findings do not agree with data provided by Haynes et al [22]) and Ronan et al. [23], who found friends and relatives as the most reliable source of trust; scientists, local/ national government and world press were also considered reliable sources of information (Haynes et al [22]). Some distrust was associated mainly to political parties $(64,3 \%)$, corporations $(55,0 \%)$ and the Government of the Azores/Religious leaders (51,4\%).

\section{Conclusion}

In spite of participants being most concerned with poverty, food and water shortage in the world, our data suggest that they are afraid of GCC.

Their perceptions indicate that the vast majority has a very good understanding of GCC processes (causes and consequences) and believes GCC is a serious threat very much linked to human activities, that most affects other (distant) parts of the world. They also believe that dangerous impacts are already happening. They perceive themselves as being reasonably well informed, get information mainly through the media and trust media more than any other source of environmental information.

Most participants reported having taken action to fight GCC, but that tendency was not expressed in daily domestic behavior. Also, responsibility for acting against GCC was mainly attributed to external powerful agents rather than to citizens and their communities.

In face of our findings, we believe that much work should be done concerning a broader approach to Azorean perceptions and attitudes regarding climate change, specially focused on changes in lifestyle, behavior patterns and 
management practices that can contribute to climate change mitigation in the archipelago.

\section{References}

[1] IPCC. Climate Change 2007 - Mitigation of Climate Change. Working Group III contribution to the Fourth Assessment Report of the IPCC. Intergovernmental Panel on Climate Change: Cambridge, 2007.

[2] Böhm, G. \& Pfister, H.-R., Mental representation of global environmental risks. Research in Social Problems and Public Policy, 9, pp. 1-30, 2001.

[3] Leiserowitz, A., American opinions on global warming, 2003. Retrieved in February 2005, from Decision Research web site: http://www.decision research.org/pdf/554.pdf

[4] Lowe, T., Vicarious experience vs. scientific information in climate change risk perception and behaviour: a case study of undergraduate students in Norwich, UK. Technical Report 43. Tyndall Centre for Climate Change Research: Norwich, 2006.

[5] Sjöberg, L., Factors in risk perception. Risk Analysis, 20(1), pp. 1- 11, 2000.

[6] Chaiken, S., Liberman, A. \& Eagly, A.H., Heuristic and systematic information processing within and behind the persuasion context. Unintended though, eds. J.S. Uleman \& J. A. Bargh., Guilford Press: New York, 1989.

[7] Sundblad, E., Biel, A. \& Gärling, T., Knowledge and Confidence in Knowledge About Climate Change Among Experts, Journalists, Politicians, and Laypersons. Environment and Behavior, 41, pp. 281-302, 2008.

[8] Renn, O. \& Levine, D., Trust and credibility in risk communication. Risk Communication, eds. H. Jungennann, R.E. Kasperson \& P.M. Wiedemann, Forschungszentrum Jülich, pp.405-413, 1991.

[9] Kasperson, R.E., The socia1 amplification of risk: progress in developing an integrative framework in social theories of risk. Social Theories of Risk, eds. S. Krimsky \& D. Golding, Praeger: Westport, CT, USA, pp.53178,992;

[10] Slovic, P., Perceived risk, trust, and democracy. Risk Analysis, 13, pp.675682, 1993.

[11] Breakwell, G.M., Social representational constrains upon identity processes. Representations of the social bridging theoretical traditions, eds. K. Deaux \& G. Philogene, pp. 271-284, Blackwell: Oxford, 2000.

[12] Kellstedt, P.M., Zahran, S., \& Vedlitz, A., Personal efficacy, the information environment, and attitudes toward global warming and climate change in the United States. Risk Analysis, 28(1), pp. 113-126, 2008.

[13] Instituto Hidrográfico, Roteiro do Arquipélago dos Açores, PUB (N) - IH128-SN, 237 pp., Lisboa, 1981.

[14] Santos, F. D., Valente, M. A., Miranda, P. M. A., Aguiar, A., Azevedo, E. B., Tomé, A. R., \& Coelho, F., Climate Change scenarios for the Açores and Madeira. World Resource Review, 16 (4), pp. 473-491, 2004. 
[15] SREA, Estimativas da População Residente, Serviço Regional de Estatística, Angra do Heroísmo, 2007.

[16] Myers, N., Mittermeier, R.A., Mittermeier, C.G., Fonseca, G.A.B. \& Kent, J., Biodiversity hotspots for conservation priorities. Nature, 403, pp. 853858, 2000.

[17] SRAM, Desafios do protocolo de Quioto na Região Autónoma dos Açores - Diagnóstico e perspectivas. SRAM, Secretaria Regional do Ambiente e do Mar, DROTRH: Ponta Delgada, 2007.

[18] Bates, B. C., Kundzewicz, Z.D., Wu, S. \& Palutikof, J.P. (Eds.), Climate change and water. Technical paper of the Intergovernmental panel on Climate Change. IPCC Secretariat: Genéve 2008.

[19] Figueiredo, M.M.M., Percepção de risco sobre alterações climáticas: estudo exploratório na ilha Terceira, Açores. Master's Thesis, Universidade dos Açores, Angra do Heroísmo, 2007.

[20] Special Barometer 300, European's attitudes towards climate change, European Commission and European Parliament, 2008

[21] Futerra, Sustainability Communications Ltd, The rules of the game: evidence base for the climate change communications strategy. Unpublished Report for the Department for Environment, Food and Rural Affairs: London, UK, 2004.

[22] Haynes, K., Barclay, J., Pidgeon, N., The issue of trust and its influence on risk communication during a volcanic crisis. Bulletin of Volcanology, 70, pp.605-621, 2008.

[23] Ronan, K.R, Johnston, D.M., Daly, M. \& Fairley, R., School Children's Risk Perceptions and Preparedness: A Hazards Education Survey, The Australasian Journal of Disaster and Trauma Studies, 1, 2000. 